\title{
Efeitos do chá verde e do exercício físico sobre a composição corporal de pessoas obesas
}

\author{
Effects of green tea and physical exercise on body \\ composition of obese people
}

Daniel Zanardini Fernandes, ${ }^{1}$ Priscila Naiverth Faix, ${ }^{1}$ Leonardo Lemke, ${ }^{1}$ Lucas Perussolo,, Vinicius Weber, ${ }^{1}$ André Luiz Kihn, ${ }^{1}$ Camila da Luz Eltchechem, ${ }^{1}$ Carlos Ricado Maneck Malfatti, ${ }^{1}$ Luiz Augusto da Silva' Universidade Estadual do Centro-Oeste (UNICENTRO), Guarapuava, PR, Brasil.

Recebido em: 17/10/2016 / Aceito em: 20/02/2017 / Publicado em: 31/03/2017 lasilva7@hotmail.com

\section{RESUMO}

Objetivo: analisar os efeitos do consumo de chá verde associado ao exercício físico sobre a composição corporal de pessoas obesas. Materiais e método: o estudo trata-se de uma revisão sistemática de literatura. As buscas foram feitas nas bases de dados Lilacs, Scielo e PubMed, utilizando os descritores: obesidade, chá verde, Camellia Sinensis, exercício. Os artigos utilizados foram publicados entre os anos de 2003 a 2015. Resultados: uma ferramenta recentemente utilizada para o controle do peso é o chá verde, considerado um alimento funcional; é a segunda bebida mais consumida no mundo. Evidências mostram seu efeito termogênico com aumento do gasto energético e promoção da oxidação de gorduras. O consumo de chá verde se mostrou efetivo na diminuição de massa corporal, especialmente na forma de gordura, porém o consumo do chá aliado à prática de exercício se mostra mais eficaz para a redução de peso. Ressalta-se ainda que os hábitos alimentares saudáveis devem ser incentivados para obter o máximo dos benefícios dessa planta. Considerações finais: é necessária a investigação mais aprofundada para determinar as doses e formas de administração seguras do chá verde, bem como os mecanismos de ação e da biodisponibilidade dos compostos ativos, pois se trata de um alimento de baixo custo e que pode ser utilizado no manejo nutricional de doenças crônicas como a obesidade, colaborando assim, para a qualidade de vida e saúde da população.

Palavras-chave: Obesidade; Chá Verde; Camellia Sinensis; Exercício.

\section{ABSTRACT}

Objective: This study is a literature review on the effects of green tea consumption associated with exercise on obesity. Materials and method: Searches were made in the databases Lilacs, SciELO and PubMed. Results: One way recently used for weight control is green tea, considered a functional food, is the second most consumed beverage in the world. Evidence shows his thermogenic effect with increased energy expenditure and promoting fat oxidation. The consumption of green tea was effective in decreasing body weight, especially in the form of fat, but tea consumption combined with exercise training proves more effective for weight reduction. It is noteworthy that healthy eating habits should be encouraged to get the maximum benefits of this plant. Closing remarks: It is required further investigation to determine the doses and secure administration of green tea, as well as the mechanisms of action and bioavailability of the active compounds, since it is an inexpensive food which can be used for the nutritional management of diseases chronic such as obesity, thus contributing to the quality of life and health.

Keywords: Obesity; Green Tea; Camellia Sinensis; Exercise.

\section{INTRODUÇÃO}

A obesidade tem sido considerada a epidemia do século $\mathrm{XXI}$, prevendo atingir $50 \%$ da população em 2025, se não houver prevenção. ${ }^{1}$ É uma doença caracterizada pela quantidade de gordura corporal acumulada, capaz de prejudicar a saúde, sendo fator de risco para outras doenças como diabetes mellitus tipo 2 , doenças 
cardiovasculares, hipertensão arterial sistêmica, dislipidemias, alguns cânceres e doença da vesícula biliar. ${ }^{2}$

Dentre os fatores de risco para o excesso de peso, alguns são modificáveis, como os maus hábitos alimentares e a inatividade física. O componente mais variável do gasto energético é a atividade física, tornando o exercício físico uma ferramenta importante para a perda de peso corporal efetiva e prevenção de novo ganho. Exercícios de treino aeróbio combinados com anaeróbios são recomendados para a perda de peso, pois o treinamento resistido aumenta a massa magra, a taxa metabólica de repouso (TMR), utilização de energia e a densidade mineral óssea (DMO) e os exercícios aeróbios melhoram o sistema cardiovascular, aumentam a queima de calorias, induzem ao déficit de energia e geram perda de gordura. ${ }^{2}$

O balanço energético positivo, consumo alimentar maior do que o gasto energético, pode ser uma das causas para o aumento de peso, bem como o aumento de refeições fora de casa, refeições rápidas hipercalóricas, redução de atividade física, facilidade no deslocamento e menor esforço no trabalho. ${ }^{3}$

A restrição calórica é o método mais utilizado para a redução de peso corporal, entretanto, deve ser incentivada uma dieta nutricionalmente equilibrada, com consumo de 50 a $55 \%$ das calorias de fontes de carboidrato, 15 a $25 \%$ de proteína e no máximo $30 \%$ de gordura. Recomenda-se a ingestão de fibras devido à promoção da saciedade, redução da densidade calórica e redução de absorção intestinal de algumas substâncias. ${ }^{2}$

A redução da ingestão de calorias na dieta e grandes períodos de privação ou restrição alimentar resultam na redução da taxa metabólica e do gasto energético, devido a interpretação pelo organismo da privação calórica que resulta no armazenamento de energia com possibilidade de ganho de peso; ${ }^{2}$ por isso a importância do acompanhamento por profissional capacitado.

Outra ferramenta recentemente utilizada para o controle do peso é o chá verde, considerado um alimento funcional; é a segunda bebida mais consumida no mundo. Evidências mostram seu efeito termogênico com aumento do gasto energético e promoção da oxidação de gorduras. Segundo a Agência Nacional de Vigilância Sanitária (ANVISA), ${ }^{4}$ a propriedade funcional do alimento é caracterizada por possuir substâncias que além da função de nutriente, apresenta benefícios relativos ao papel fisiológico ou metabólico que apresenta no crescimento, desenvolvimento e manutenção das funções normais do organismo.

Estudos mostram que o consumo de chá verde aliado à prática de exercício físico auxilia no maior ganho de massa magra e maior perda de gordura comparado à prática de exercício físico isolado, além de aumento de força muscular, quando consumido antes da prática. ${ }^{5}$

Diante do exposto, o objetivo do trabalho é revisar a literatura, quanto ao consumo de chá verde associado à prática de exercício físico na modificação da composição corporal e benefícios à saúde.

\section{MATERIAIS E MÉTODO}

Este trabalho trata-se se uma revisão de literatura sobre os efeitos do consumo de chá verde associado ao exercício físico sobre a obesidade. As buscas foram feitas nas bases de dados Lilacs, Scielo e PubMed utilizando os descritores em português e inglês: chá verde, obesidade, Camellia Sinensis, exercício, green tea, obesity e exercise e suas combinações durante o período de maio a junho de 2016.

Foram inclusos artigos completos e disponíveis gratuitamente. Após pesquisa, foram encontrados 62 artigos, destes, foram selecionados 32 em língua inglesa e 19 em língua portuguesa. Foram excluídos 14 artigos em língua espanhola ou castelhano. Restando assim, 50 artigos. Após leitura breve do resumo dos artigos, foram descartados 24 artigos que se mostraram irrelevantes ao estudo, restando então 26 artigos. Após uma leitura aprofundada de cada artigo, foram descartados mais 9 artigos, chegando assim a 17 artigos usados na construção deste estudo.

Os artigos não foram selecionados levando em conta a sua data de publicação, embora todos tenham sido publicados entre os anos de 2003 e 2015.

\section{RESULTADOS E DISCUSSÃO}

O chá das folhas de Camellia sinensis é a segunda bebida mais consumida no mundo depois da água. Produzido a partir dessa planta, podem ser classificados de acordo com o processo de fabricação, sendo o chá verde não fermentado, o que tem em sua composição $30 \%$ de polifenois, oferecendo mais benefícios em comparação ao chá preto e oolong que são oriundos da mesma erva. ${ }^{6,7}$ As folhas dessa erva apresentam mais de 2000 componentes, porém a composição pode variar de acordo com o local de cultivo, época de colheita e processo de beneficiamento. ${ }^{6}$

Revelou-se um alimento funcional considerado um antioxidante efetivo, pois protege o DNA contra lesões, quando induzido em laboratório; interrompe a iniciação e o progresso do crescimento de tumor canceroso e estimula a apoptose. Contra doenças cardíacas, evita a oxidação de LDL-c, inibindo formação de ateromas, ${ }^{7}$ devido a sua composição química que apresenta polifenois, sendo a maior parte composta por catequinas. Em quantidades significativas existem a epicatequina (EC), epigalocatequina (EGC), galato de epicatequina e galato de epigalocatequina (EGCG); esta última com maior potencial antioxidante apresentando cerca de 25 a 100 vezes mais comparado a vitaminas $\mathrm{C}$ e $\mathrm{E}$ e representa de 10 a $50 \%$ do total das catequinas. ${ }^{7}$

Além das propriedades antioxidantes, as catequinas do chá verde promovem a perda de peso, essa evidência se deve ao consumo do chá suprimir a ingestão de alimentos, bem como o ganho de peso e acúmulo de gordura, além de aumentar a taxa metabólica, devido ao seu efeito termogênico, possivelmente pela elevação dos níveis de norepinefrina. ${ }^{7}$ Essa elevação acontece devido aos flavonoides da planta inibirem a catecol-O-metiltransferase, enzima que degrada o neurotransmissor norepinefrina, fazendo seu efeito no gasto energético e oxidação de lipídeos permanecer por tempo prolongado. ${ }^{6}$

Outra hipótese para tais efeitos é de que a cafeína, naturalmente presente na composição do chá, age sinergicamente com as catequinas, ocorrendo aumento 
do gasto energético e oxidação de lipídeos, relativa à atividade do sistema nervoso simpático (SNS). Outros mecanismos envolvem a redução do apetite, regulação de enzimas envolvidas na oxidação de gordura hepática e diminuição da absorção de gorduras. ${ }^{8}$

A fim de obter os efeitos benéficos do chá verde, sugere-se o consumo de quatro a seis xícaras ao dia entre as refeições para não haver interações com os nutrientes dos alimentos, mantendo sua biodisponibilidade. A concentração de galato de epigalocatequina (GECG) fica em torno de $1 \mu \mathrm{m}$ no plasma, após 1 hora de ingestão de chá verde, sugerindo que a ingestão deve ser fracionada. ${ }^{9}$

A forma de preparo deve ser observada, de modo a despejar a água antes da ebulição sobre as folhas e manter em infusão de dois a três minutos. A proporção deve ser de duas colheres da erva seca ou quatro colheres da erva fresca para cada litro de água. ${ }^{10}$

Um estudo que envolveu homens e mulheres com sobrepeso foi realizado durante três meses, sendo os indivíduos divididos em grupos que ingeriram chá verde enriquecido com diferentes conteúdos de catequinas e cafeína. O grupo que ingeriu maior quantidade dessas substâncias ( $886 \mathrm{mg}$ de catequinas e $198 \mathrm{mg}$ de cafeína) apresentou diferença significativa na redução de peso e circunferência da cintura em relação ao grupo controle que ingeriu somente $30 \mathrm{mg}$ de catequinas e $10 \mathrm{mg}$ de cafeína. Entretanto, o grupo que consumiu quantidades intermediárias de catequinas e cafeína, $468 \mathrm{mg}$ e $126 \mathrm{mg}$ respectivamente, apresentou maior percentual de perda de gordura, após o período de intervenção, mostrando um efeito desproporcional na perda de massa corporal. ${ }^{11}$

O consumo de chá verde associado à pratica de exercício físico parece elevar o seu potencial energético, tornando-se aliado ao emagrecimento. O gasto energético é modulado pela composição corporal, assim faz parte dos programas para perda de peso, promoção do aumento da massa magra e diminuição de gordura, o que resulta na elevação da taxa metabólica em resposta à atividade física. ${ }^{2}$

Estudos mostram que exercício aeróbico moderado três vezes por semana produz melhora significativa em parâmetros antropométricos com perda de peso e redução da circunferência abdominal, hemodinâmicos e metabólicos em pacientes inativos fisicamente, mesmo em pequeno período de prática. ${ }^{12}$

Estudo duplo cego realizado por Gahreman et al. ${ }^{13}$ combinou exercício físico (Intermittent Sprinting Exercise) e consumo de extrato de chá verde em mulheres destreinadas que se julgavam saudáveis, divididas em um grupo placebo e outro que consumiu o extrato. Durante quatro semanas ingeriram as cápsulas no dia anterior e no dia do exercício físico. Após a ingestão e no período de repouso antes do exercício, houve aumento significativo de $24 \%$ da oxidação de gorduras. No período de 35 a 75 minutos após o exercício, a taxa de oxidação se elevou para $29 \%$, aumento significativo comparado ao grupo placebo. Houve aumento significativo do consumo de oxigênio do grupo que ingeriu o extrato comparado ao grupo placebo. As catequinas atingiram seu pico sanguíneo entre 1,3 e 1,6h.

Em estudo conduzido por Ota et al. ${ }^{14}$ buscou-se analisar a combinação da ingestão de catequinas do chá verde com exercício físico, durante dois meses. Participaram quatorze homens saudáveis, dos quais sete foram considerados grupo controle e receberam bebida placebo e os outros receberam bebida, contendo $570 \mathrm{mg}$ de catequinas antes ou após o treino, foram submetidos a treino físico três vezes por semana. Concluiu-se que independentemente da prática de atividade física, o gasto energético foi maior nos indivíduos que consumiram as catequinas. Entretanto, a combinação da prática do exercício físico regular com a ingestão de catequinas, aumenta a mobilização de gordura corporal como fonte energética devido à estimulação do metabolismo de gorduras no fígado e músculo esquelético. ${ }^{14}$

Vera-Cruz et al. ${ }^{15}$ induziu ratos à obesidade por meio de dieta hipercalórica e os submeteu ao tratamento com chá verde, os quais ingeriram $2 \mathrm{ml}$ de chá preparado com folhas secas de chá verde, durante duas semanas. O grupo de animais que ingeriu o chá apresentou significativa perda de peso corporal, em relação ao que não recebeu tratamento. ${ }^{15}$

Cardoso et al. ${ }^{3}$ estudou um grupo de mulheres com Índice de Massa Corporal (IMC) entre $25 \mathrm{~kg} / \mathrm{m}^{2}$ a $35 \mathrm{~kg} / \mathrm{m}^{2}$ sedentárias e que não faziam uso de chá verde. Durante um mês passaram por adaptações na alimentação. Nos dois meses seguintes, faziam uso ou não de chá verde e exercício físico de força. As participantes foram induzidas a tomar o chá verde ou placebo 10 minutos antes do exercício. Embora não significativa, a perda de peso ocorreu somente no grupo que consumiu chá verde, demonstrando seu efeito termogênico, com manutenção de massa magra e redução de gordura.

No grupo que consumiu chá verde e praticou exercício não houve diminuição da massa corporal, porém obteve resultados significativos no aumento da massa magra, diminuição de gordura e da circunferência abdominal. Observou-se também um aumento de $36 \%$ na TMR em relação ao início do consumo de chá verde. ${ }^{5}$

O exercício físico de resistência aliado a alimentação adequada auxilia na manutenção ou aumento dos músculos, auxiliando a perda de peso e equilíbrio da taxa metabólica de repouso (TMR). ${ }^{2}$

Em ratos, a ingestão de chá aliado à atividade física demonstrou aumento da capacidade de resistência aos exercícios, bem como promover a beta oxidação de gorduras no fígado e no tecido adiposo. O efeito contra obesidade pode ser devido à diminuição de enzimas lipolíticas, dificultando absorção de gorduras, além de aumento de quantidade e atividade de enzimas que quebram adipócitos. ${ }^{16}$

Outro estudo utilizando ratas obesas demonstrou que a suplementação de chá verde tem potente efeito sobre o peso corporal, através da regulação de genes relacionados com a obesidade, bem como atividade anti-inflamatória, antioxidante e a ação do estrógeno, sugerindo mais investigações sobre a eficácia do chá verde em mulheres obesas. ${ }^{17}$

Apesar de serem descritos os efeitos benéficos a esta planta, é necessário atenção aos efeitos adversos que o consumo pode apresentar, como descrito por Bartels et al. ${ }^{18}$ que relatou que o consumo diário de $65 \mathrm{~g}$ de folhas por 5 anos pode levar à disfunção hepática, diminuição do apetite, insônia, aumento dos batimentos cardíacos e irritação gástrica, embora esses efeitos tam- 
bém possam ser relativos à cafeína. Chama-se a atenção para a quantidade de folhas consumidas nesses estudos que se mostra superior ao consumido normalmente.

\section{CONSIDERACQÕES FINAIS}

Como nos mostra a literatura aqui analisada, o chá de Camellia Sinensis, é um grande auxiliar como acelerador metabólico e antioxidante, auxiliando assim na diminuição do percentual de gordura e redução da massa corporal, isso combinado ao exercício físico, traz ganhos para a saúde, principalmente em casos de obesidade.

Para elucidar a utilização do chá verde devem ser realizados mais estudos a fim de discutir qual a influência da cafeína consumida concomitantemente às catequinas, bem como a influência da dose consumida, se consumida antes, durante ou após a ingestão de alimentos, a duração do tratamento, grau de adiposidade e a interação com a atividade física, merecendo mais investigações sobre o assunto.

\section{REFERÊNCIAS}

1. World Health Organization. Global health risks: mortality and burden of disease attributable to selected major risks. WHO; 2009. Disponível em: url:http://www.who.int/healthinfo/ global _ burden _ disease/GlobalHealthRisks _ report _ full. pdf World Health Organization. Global health risks: mortality and burden of disease attributable to selected major risks. WHO; 2009. Disponível em: <http://www.who.int/ healthinfo/global_burden _disease/GlobalHealthRisks report_full.pdf $>$.

2. Mahan L, Escott-Stump S. Krause, alimentos, nutrição e dietoterapia. $12^{\mathrm{a}}$ ed. Rio de Janeiro: Elsevier; 2010.

3. Jaime PC, Silva ACF, Gentil PC, Claro RM, Monteiro AC. Brazilian obesity prevention and control initiatives obesity reviews. Obes Ver 2013;14(Supl. 2):88-95.

4. ANVISA - Agência Nacional de Vigilância Sanitária. Resolução- RDC n¹8, de 30 de abril de 1999. Aprova o regulamento técnico que estabelece as diretrizes básicas para análise e comprovação de propriedades funcionais e/ou de saúde alegadas em rotulagem de alimentos. [acesso 2016 jun 20]. Disponível em: <http://www.anvisa.gov.br>.

5. Cardoso GA, Salgado JM. Efeito do consumo de chá verde aliado ou não ao treinamento de força sobre a composição corporal e taxa metabólica de repouso em mulheres com sobrepeso ou obesas [tese de mestrado]. Piracicaba: Escola Superior de Agricultura Luiz de Queiroz; 2011 Cardoso GA,
Salgado JM. Efeito do consumo de chá verde aliado ou não ao treinamento de força sobre a composição corporal e taxa metabólica de repouso em mulheres com sobrepeso ou obesas [tese de mestrado]. Piracicaba: Escola Superior de Agricultura Luiz de Queiroz; 2011

6. Shixian Q, Vancrey B, Shi J, Kakuda Y, Jiang Y. Green tea extract thermogenesis-induced weight loss by epigallocatechin gallate inhibition of catechol-Omethyltransferase. J Medicinal Food 2006;9:451-458. doi: 10.1089/jmf.2006.9.451

7. Talbott, S. M.; Hughes, K. Suplementos Dietéticos: Guia para profissionais da saúde. Rio de Janeiro: Guanabara Koogan; 2015.

8. Rains TM, Agarwal S, Maki KC. Antiobesity effects of green tea catechins: a mechanistic review. Journal of Nutritional Biochemistry 2011;22(1): 1-7. doi: 10.1016/j. jnutbio.2010.06.006

9. Lamarão RC, Fialho E. Aspectos funcionais das catequinas do chá verde no metabolismo celular e sua relação com a redução da gordura corporal. Rev Nutrição 2009;22(2):257-269.

10. ADA Reports. Position of the American Dietetic Association: functional foods. J Am Diet Assoc 2004;104(5):814-26.

11. Wang H, Wen $Y$, Du Y, Yan X, Guo H, Rycroft JA, et al. Effects of catechin Enriched green tea on body composition. Obesity 2010;18(4):773-779. doi: 10.1038/oby.2009.256

12. Colombo CM, Macedo RM, Fernandes-Silva MM, Caporal $A M$, Stinghen $A E$, Constantini $C R$, et al . Efeitos de curto prazo de um programa de atividade física moderada em pacientes com síndrome metabólica. Einstein 2013;11(3):324-330.

13. Gahreman D, Wang R, Boutcher Y, Boutcher S. Green Tea, Intermittent Sprinting Exercise, and Fat Oxidation. Nutrients 2015;7:5646-5663. doi: 10.3390/nu7075245

14. Ota N, Soga S, Shimotoyodome A, Haramizy S, Inaba M, Murase $\mathrm{T}$, et al. Effects of combination of regular exercise and tea catechins intake on energy expenditure in humans. J Health Science 2005;51(2):233-6. doi: 10.1248/jhs.51.233

15. Vera-Cruz M, Nunes E, Mendonça L, Chaves E, Fernandes M. Efeito do chá verde (Camelia sinensis) em ratos com obesidade induzida por dieta hipercalórica. J Bras Patol Med Lab 2010;46(5):407-413.

16. Wolfram S, Wang Y, Thielecke F. Anti-obesity effects of green tea: from bedside to bench. Molecular Nutrition Food Research 2006;50:176-187.

17. Lu C, Zhu W, Shen C, Gao W. Green Tea Polyphenols Reduce Body Weight in Rats by Modulating Obesity-Related Genes. PloS ONE 2012:7(6). doi: 10.1371/journal.pone.0038332

18. Bartels CL, Miller SJ. Dietary supplements marketed for weight loss. Nutr Clin Pract 2003;18:156-69. doi: $10.1177 / 0115426503018002156$

Como citar: FERNANDES, Daniel Zanardini et al. Efeitos do chá verde e do exercício físico sobre a composição corporal de pessoas obesas. Cinergis, Santa Cruz do Sul, v. 18, n. 2, mar. 2017. ISSN 2177-4005. Disponível em: < https://online.unisc.br/seer/index. php/cinergis/article/view/8438>. Acesso em: 29 mar. 2017. doi: http://dx.doi.org/10.17058/cinergis.v18i2.8438. 